\title{
Hormetic Concentrations of Hydrogen Peroxide but Not Ethanol Induce Cross-Adaptation to Different Stresses in Budding Yeast
}

\author{
Halyna M. Semchyshyn \\ Department of Biochemistry and Biotechnology, Vassyl Stefanyk Precarpathian National University, \\ 57 Shevchenko Street, Ivano-Frankivsk 76025, Ukraine \\ Correspondence should be addressed to Halyna M. Semchyshyn; semchyshyn@pu.if.ua
}

Received 31 July 2013; Revised 23 October 2013; Accepted 23 October 2013; Published 14 January 2014

Academic Editor: Giuseppe Comi

Copyright (C) 2014 Halyna M. Semchyshyn. This is an open access article distributed under the Creative Commons Attribution License, which permits unrestricted use, distribution, and reproduction in any medium, provided the original work is properly cited.

\begin{abstract}
The biphasic-dose response of microorganisms to hydrogen peroxide is a phenomenon of particular interest in hormesis research. In different animal models, the dose-response curve for ethanol is also nonlinear showing an inhibitory effect at high doses but a stimulatory effect at low doses. In this study, we observed the hormetic-dose response to ethanol in budding yeast $S$. cerevisiae. Cross-protection is a phenomenon in which exposure to mild stress results in the acquisition of cellular resistance to lethal stress induced by different factors. Since both hydrogen peroxide and ethanol at low concentrations were found to stimulate yeast colony growth, we evaluated the role of one substance in cell cross-adaptation to the other substance as well as some weak organic acid preservatives. This study demonstrates that, unlike ethanol, hydrogen peroxide at hormetic concentrations causes cross-resistance of S. cerevisiae to different stresses. The regulatory protein Yap1 plays an important role in the hormetic effects by low concentrations of either hydrogen peroxide or ethanol, and it is involved in the yeast cross-adaptation by low sublethal doses of hydrogen peroxide.
\end{abstract}

\section{Introduction}

Organisms' adaptation to environmental stress has become a subject of great interest over the last decades [1-5]. Like other organisms, budding yeast Saccharomyces cerevisiae has developed several strategies to survive stressful changes in their environment. Sudden challenge can result in disturbance of cellular functions or even cell death. Clearly, yeast cells respond rapidly and modify their internal systems to prevent dramatic events. Depending on the intensity and type of stress, many different mechanisms contribute to the development of yeast resistance to stressful changes.

It is widely believed that cell exposure to mild stress results in the acquisition of cellular resistance to further lethal stress, what is called "adaptive response" or "preadaptation" $[6,7]$. The phenomenon has been observed in various organisms: from bacteria to humans. In many cases, an exposure to mild stress develops tolerance not only to higher doses of the same stressor but also to stress caused by other factors. This phenomenon, known as "cross-protection" or "cross-adaptation" $[6,7]$, suggests the existence of complex mechanisms, which sense and respond to different kinds of stress. The literature includes data on S. cerevisiae general response, pre-adaptation, and cross-adaptation to extreme temperatures, osmotic shock, and oxidative stress [2, 6, 8-12].

There is information on the increased resistance to severe stress in yeast preexposed to mild sublethal stress, which requires the global-stress transcription factors Msn2/4p to regulate induction of the so-called environmental stress response genes [6, 11]. Activation of Msn2/4p, in particular, is an important way to induce antioxidant defense against hydrogen peroxide $[13,14]$. Yaplp transcriptional regulatory protein also mediates an adaptive response of yeast to $\mathrm{H}_{2} \mathrm{O}_{2}$ induced stress $[4,9,13-15]$. Sublethal hormetic concentrations of hydrogen peroxide are believed to induce a protective response with increased resistance to subsequent lethal stress in yeast cells $[6,7,10,16]$. However, unlike Msn2/4p, the potential role of Yaplp in the cross-adaptation phenomenon is poorly investigated.

Yaplp is found to be localized in the cytoplasm under nonstressful conditions, but upon exposure to hydrogen peroxide it rapidly translocates to the nucleus and changes 
the expression of target genes [17-19]. Although Yaplp was earlier suggested to play a minor role in the regulation of gene expression under ethanol stress [20], like $\mathrm{H}_{2} \mathrm{O}_{2}$, ethanol was recently found to trigger Yap1 nuclear accumulation and activate some antioxidant enzymes in S. cerevisiae [21].

In the present study, we have shown that low hormetic concentrations of hydrogen peroxide as well as ethanol stimulated yeast colony growth. Therefore, we evaluated the role of one substance in cell cross-adaptation to the other substance as well as some weak organic acid preservatives, and potential role of Yaplp in yeast cross-adaptation by hormetic concentrations of hydrogen peroxide and ethanol to stressful conditions.

\section{Materials and Methods}

2.1. Yeast Strains and Growth Conditions. The Saccharomyces cerevisiae strains used in this study are YPH250 (wild type:

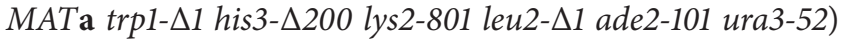

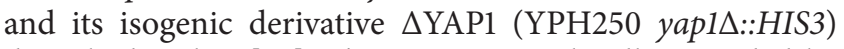
described earlier [22]. The strains were kindly provided by Professor Yoshiharu Inoue (Kyoto University, Japan).

Yeast cells were grown in Erlenmeyer flasks containing YPD liquid medium (1\% yeast extract, $2 \%$ peptone, and $2 \%$ glucose) in a volume that respected the ratio 1:5 regarding media volume to flask volume. Cells were grown with shaking at 175 r.p.m., $28^{\circ} \mathrm{C}$, and $\mathrm{pH} 7.0$ for $24 \mathrm{~h}$ to late exponential phase $\left(A_{600} \sim 0.8-0.9\right)$.

2.2. Preincubation and Stress Induction. The experimental culture after growth under the conditions mentioned above was split into three groups: one exposed to stress, another preadapted by low concentrations of hydrogen peroxide or ethanol and then exposed to stress, and the last one serving as a control to which none of the abovementioned substances was added.

For stress induction, aliquots of experimental culture were incubated at $28^{\circ} \mathrm{C}$ with $50 \mathrm{mM} \mathrm{H}_{2} \mathrm{O}_{2}$ for $30 \mathrm{~min}, 15 \%$ or $20 \%$ ethanol for $60 \mathrm{~min}$, and $200 \mathrm{mM}$ acetic or $100 \mathrm{mM}$ propionic acid for $120 \mathrm{~min}$. At low $\mathrm{pH}$, acetic acid $\left(\mathrm{pK}_{\mathrm{a}} 4.75\right)$ and propionic acid $\left(\mathrm{pK}_{\mathrm{a}} 4.88\right)$ exist mainly in the undissociated state, in which they enter the cell rather easily [23]. For acid stress, the $\mathrm{pH}$ value of YPD medium was adjusted to 3.0 with $\mathrm{HCl}$ in order to reach maximum penetration of the acids into cells $[24,25]$. Under stress induced by hydrogen peroxide or ethanol the $\mathrm{pH}$ value of YPD medium was 7.0.

To study the preadaptation effect on cell survival under stress, aliquots of experimental culture were preincubated with $0.05,0.25$, and $0.5 \mathrm{mM} \mathrm{H}_{2} \mathrm{O}_{2}$ or $1 \%, 2.5 \%$, and $5 \%$ ethanol at $28^{\circ} \mathrm{C}$ and $\mathrm{pH} 7.0$ for 30 or 60 minutes, respectively.

Control cells were incubated under the same conditions but without hydrogen peroxide, ethanol, acetate, or propionate. In preliminary experiments, it was shown that yeast colony growth was virtually the same at $\mathrm{pH} 3.0$ and $7.0[7,26]$. Thus, control cells for acetate- and propionate-induced stress were incubated in YPD medium at $\mathrm{pH} 3.0$ without organic acids.

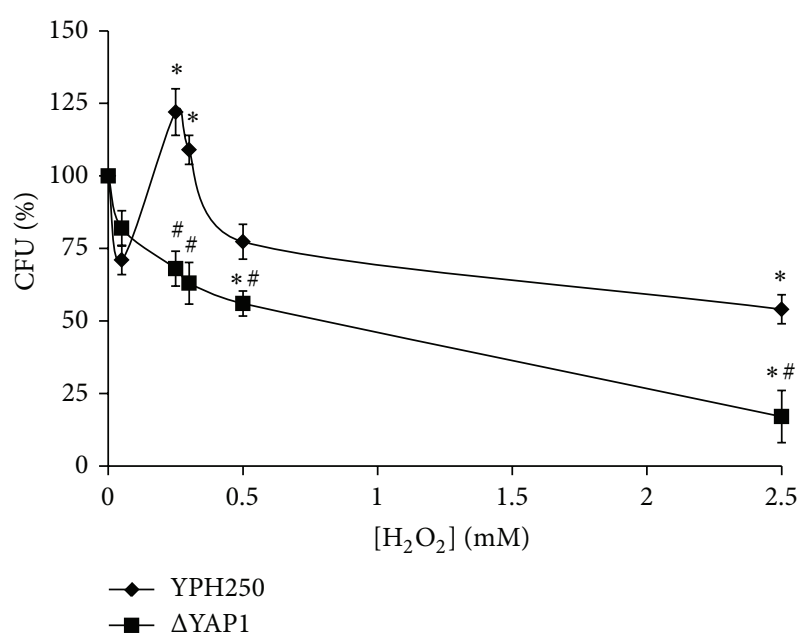

FIGURE 1: Colony forming units of S. cerevisiae YPH250 and its derivative $\triangle$ YAP1 after exposure to different concentrations of hydrogen peroxide. Significantly different from respective values obtained for S. cerevisiae YPH250 with $P<0.05^{\#}$, and for corresponding cells treated with $0.05 \mathrm{mM} \mathrm{H}_{2} \mathrm{O}_{2}$ with $P<0.05^{*}$. Data are mean \pm SEM $(n=4-6)$.

2.3. Evaluation of Yeast Colony Growth and Statistical Analysis. Yeast colony growth was analyzed by plating in triplicate on YPD agar after proper dilution. The plates were incubated at $28^{\circ} \mathrm{C}$ for 3 days and the colony forming units (CFU) were counted [27]. Yeast colony growth was expressed as percentage of total amount of respective control cells plating on YPD agar.

Experimental data are expressed as the mean value of 46 independent experiments \pm the standard error of the mean (SEM), and statistical testing used Student's $t$-test.

\section{Results and Discussion}

The biphasic-dose response to hydrogen peroxide is the phenomenon of particular interest in hormesis research $[8,28-$ 31]. In the case of budding yeast, special attention is focused on the concentrations of hydrogen peroxide $(\leq 0.4 \mathrm{mM})$ found to stimulate yeast colony growth by about $30 \%$ (stimulatory/hormetic zone) [8]. At the same time, hydrogen peroxide has been shown to induce cell toxicity at concentrations higher than $0.5 \mathrm{mM}$. Earlier, the nonlinear dependence of S. cerevisiae RZ53-6 survival on different concentrations of hydrogen peroxide was demonstrated by Davies and colleagues [8]. In the present study, we observed nonlinear dependence of $S$. cerevisiae YPH250 viability on different levels of $\mathrm{H}_{2} \mathrm{O}_{2}$ (Figure 1). Since $\mathrm{H}_{2} \mathrm{O}_{2}$ low concentrations $(\leq 0.5 \mathrm{mM})$ inhibited significantly the colony growth of $\Delta$ yap1 mutant derived from YPH250 wild type (Figure 1), we suggested Yaplp involvement in hormetic effect by low doses of hydrogen peroxide in the parental strain.

In different animal models, the dose-response curve for ethanol is also biphasic showing an inhibitory effect at high doses but a stimulatory effect at low doses $[32,33]$. We observed non-linear dose response to ethanol in S. cerevisiae 


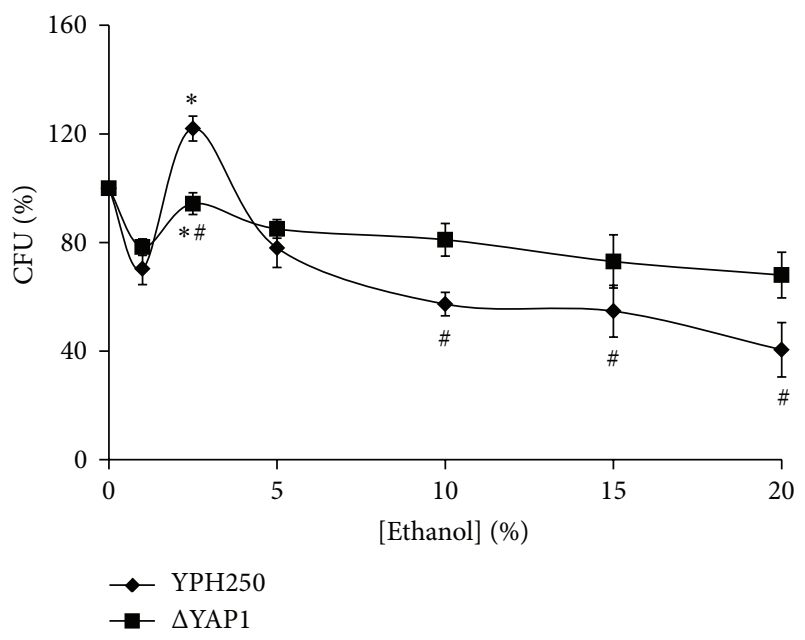

FIgure 2: Colony forming units of S. cerevisiae YPH250 and its derivative $\triangle \mathrm{YAP1}$ after exposure to different concentrations of ethanol. Significantly different from respective values obtained for $S$. cerevisiae YPH250 with $P<0.05^{\#}$, and for corresponding cells treated with $1 \%$ ethanol with $P<0.05^{*}$. Data are mean \pm SEM $(n=$ $4-6)$.

YPH250 wild strain (Figure 2). Yeast ability to form colonies in cultures treated with $1 \%$ ethanol was decreased by $30 \%$ comparing to untreated control cells. Cells exposed to $2.5 \%$ ethanol demonstrated percent colony growth that exceeded the original control value by about $20 \%$. At the higher concentrations used $(\geq 5 \%)$, ethanol significantly inhibited yeast colony growth.

Figure 2 demonstrates also the influence of different concentrations of ethanol on the reproductive ability of $\Delta y a p 1$ mutant isogenic derivative of YPH250. Generally, the effect is somewhat similar to that obtained for YPH250 parental strain. Exposure of $\Delta y a p 1$ cells to $1 \%$ ethanol decreased colony growth by $22 \%$. It should be noted that $2.5 \%$ ethanol increased the parameter comparing with that found for cells exposed to $1 \%$ ethanol, but colony growth of the $\Delta y a p 1$ cells treated with $2.5 \%$ ethanol did not exceed the initial control value. We also supposed that Yap1 regulatory protein was involved in some way in the stimulation of yeast colony growth under stress induced by $2.5 \%$ ethanol (Figure 2).

The Yap1 transcription factor controls the expression of over 150 genes in the response of $S$. cerevisiae to hydrogen peroxide [34-36]. Since most of them were found to play an important role in yeast survival under $\mathrm{H}_{2} \mathrm{O}_{2}$-induced stress, we expected that Yaplp was involved in hormetic effect by hydrogen peroxide. At the same time, there are somewhat controversial data regarding Yaplp activation by ethanol. Earlier Yaplp was suggested to play a minor role in regulation of gene expression under ethanol stress in S. cerevisiae [37]; however, ethanol was recently found to trigger Yap1 nuclear accumulation and to activate some antioxidant enzymes in the yeast [21].

Since both hydrogen peroxide and ethanol at low concentrations were found to stimulate the colony growth of $S$. cerevisiae wild type, next we evaluated the role of one substance

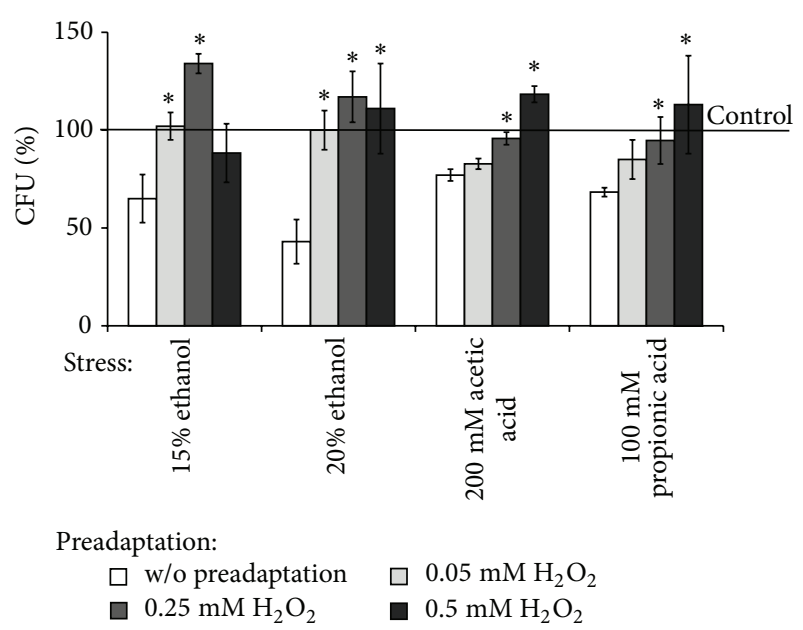

FIGURE 3: Colony forming units of S. cerevisiae YPH250 cells pretreated with low concentrations of $\mathrm{H}_{2} \mathrm{O}_{2}$ under exposure to different stresses. ${ }^{*}$ Significantly different from respective values obtained for cells with $P<0.05$. Data are mean \pm SEM $(n=5-6)$.

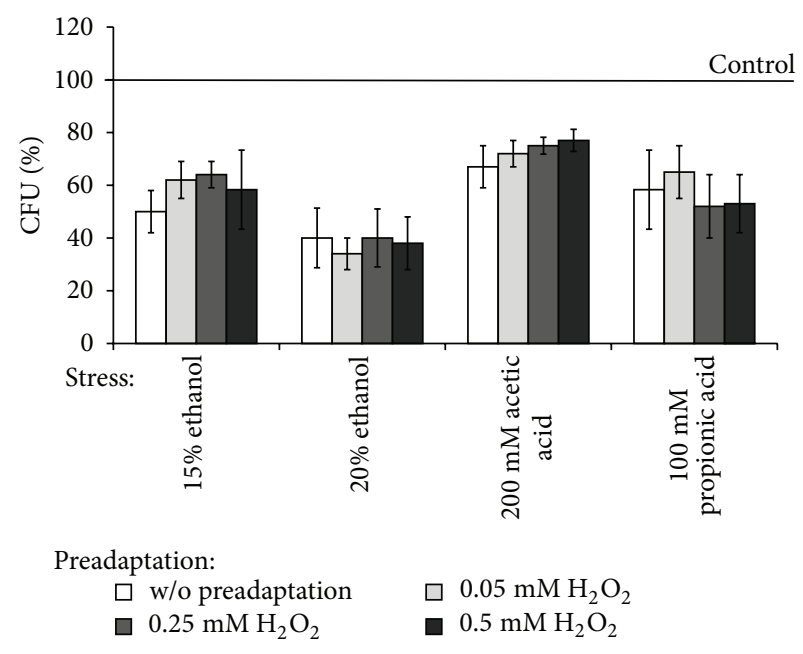

FIGURE 4: Colony forming units of $\triangle \mathrm{YAP1}$ mutant pretreated with low concentrations of $\mathrm{H}_{2} \mathrm{O}_{2}$ under exposure to different stresses. Data are mean \pm SEM $(n=4-6)$.

in cell cross-adaptation to the other substance as well as some weak organic acid preservatives. Figure 3 shows the effect of yeast pretreatment with low $\mathrm{H}_{2} \mathrm{O}_{2}$ concentrations on its reproductive ability under stress induced by ethanol, acetate, and propionate. As seen in the figure, all the stressors significantly inhibited colony growth of S. cerevisiae YPH250 (by $35 \%, 57 \%, 23 \%$, and $32 \%$ in response to $15 \%$ or $20 \%$ ethanol and $200 \mathrm{mM}$ acetate or $100 \mathrm{mM}$ propionate, resp.). Yeast pretreatment with hormetic doses of hydrogen peroxide markedly increased reproductive ability under the stressful conditions. For example, the highest colony growth (134\% and $118 \%$ comparing to control untreated cells) was observed in yeast preincubation with $0.25 \mathrm{mM} \mathrm{H}_{2} \mathrm{O}_{2}$ and then stressed by $15 \%$ or $20 \%$ ethanol. In the case of weak organic acids, 


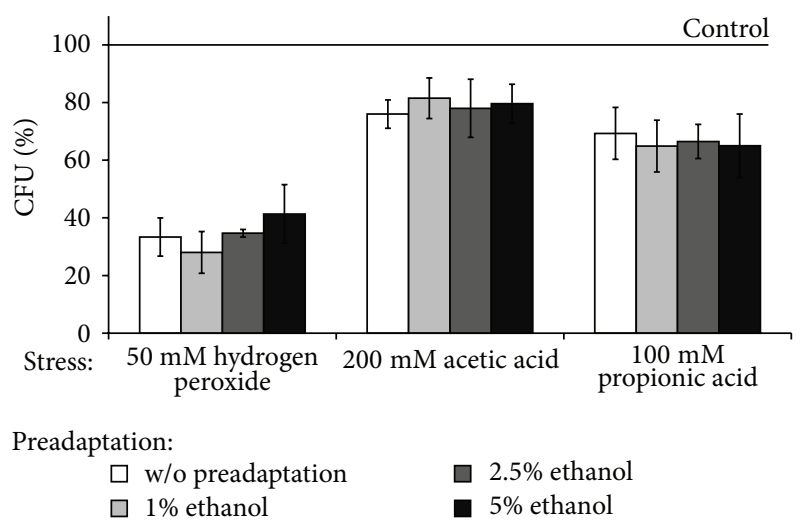

FIGURE 5: Colony forming units of S. cerevisiae YPH250 cells pretreated with low concentrations of ethanol under exposure to different stresses. Data are mean $\pm \operatorname{SEM}(n=5-6)$.

the highest reproductive ability was observed in yeast pretreated with $0.5 \mathrm{mM} \mathrm{H}_{2} \mathrm{O}_{2}(118 \%$ and $113 \%$ for acetate- and propionate-exposed cells, resp.).

Hydrogen peroxide is known to affect expression of a variety of genes involved in signal transduction, transcriptional regulation, antioxidant defence, and protein, carbohydrates, or lipid metabolism in different organisms [9, 12-14, 29, 35-39]. That is why at low hormetic concentrations, $\mathrm{H}_{2} \mathrm{O}_{2}$ may act as an important signal molecule stimulating various defensive mechanisms and enhancing survival of yeast cells under lethal stress.

It should be noted that, comparing to the wild type, $\Delta y a p 1$ mutant demonstrated significantly higher sensitivity to all the types of stressors and no cross-adaptation by low concentrations of hydrogen peroxide to any stressors used (Figure 4). The latter confirms an important role of Yaplp in cross-adaptation effect by hormetic doses of hydrogen peroxide in parental YPH250 strain.

Earlier it was suggested that depending on strain genotype, ethanol either provided or did not provide yeast protection against environmental stress [6]. Despite the fact that yeast cells demonstrated non-linear dose response to ethanol (Figure 2), we did not observe any stimulatory effect by ethanol preadaptation on colony growth of yeast under stressful conditions (Figure 5). As seen, $50 \mathrm{mM} \mathrm{H}_{2} \mathrm{O}_{2}, 200 \mathrm{mM}$ acetate, and $100 \mathrm{mM}$ propionate inhibited S. cerevisiae YPH250 ability to form colonies by $33 \%, 76 \%$, and $69 \%$, respectively, and preexposure of yeast by ethanol did not change the parameter. As seen in Figure 6, $\Delta$ yap1 mutant demonstrated much higher sensitivity to all the types of stressors comparing to wild type as well as no cross-adaptation by ethanol to any stressors used.

\section{Conclusion}

This study demonstrates that, unlike ethanol, hormetic concentrations of hydrogen peroxide cause cross-resistance of S. cerevisiae YPH250 to different stresses. The regulatory protein Yapl plays an important role in the hormetic effects caused by low concentrations of either hydrogen peroxide or

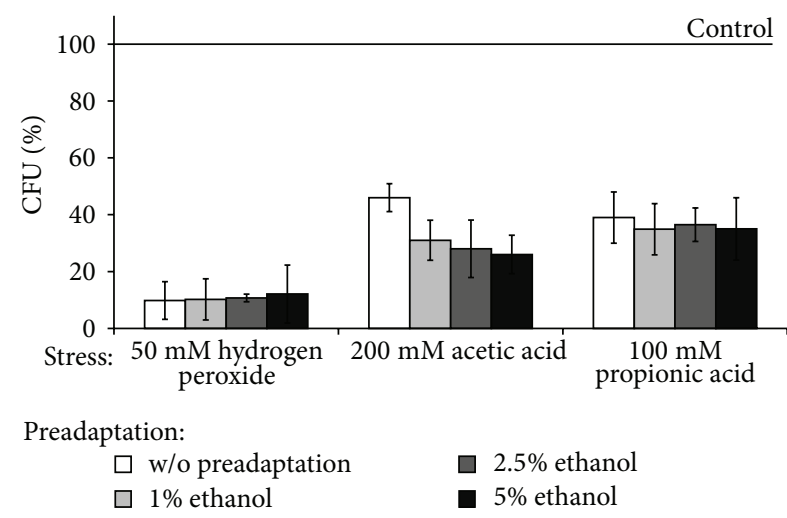

FIGURE 6: Colony forming units of $\triangle \mathrm{YAP1}$ mutant pretreated with low concentrations of ethanol under exposure to different stresses. Data are mean \pm SEM $(n=4-5)$.

ethanol, and it is involved in the yeast cross-adaptation to stressful conditions by low sublethal doses of hydrogen peroxide.

\section{Conflict of Interests}

The author declares that there is no conflict of interests regarding the publication of this article.

\section{Acknowledgments}

The author is grateful to Professor Yoshiharu Inoue for providing the yeast strains and Professor Volodymyr Lushchak for critical reading of the paper. The author would like to express sincere gratitude and appreciation to HanseWissenschaftskolleg Institute for Advanced Study for providing creative and intense work atmosphere, in which the paper has been prepared.

\section{References}

[1] C. Lexer and M. F. Fay, "Adaptation to environmental stress: a rare or frequent driver of speciation?" Journal of Evolutionary Biology, vol. 18, no. 4, pp. 893-900, 2005.

[2] P. González-Párraga, R. Sánchez-Fresneda, M. MartínezEsparza, and J. C. Argüelles, "Stress responses in yeasts: what rules apply?" Archives of Microbiology, vol. 189, no. 4, pp. 293296, 2008.

[3] D. B. Berry, Q. Guan, J. Hose et al., "Multiple means to the same end: the genetic basis of acquired stress resistance in yeast," PLoS Genetics, vol. 7, no. 11, Article ID e1002353, 2011.

[4] V. I. Lushchak, "Adaptive response to oxidative stress: bacteria, fungi, plants and animals," Comparative Biochemistry and Physiology C, vol. 153, no. 2, pp. 175-190, 2011.

[5] D. Demirovic and S. I. S. Rattan, "Establishing cellular stress response profiles as biomarkers of homeodynamics, health and hormesis," Experimental Gerontology, vol. 48, no. 1, pp. 94-98, 2012.

[6] D. B. Berry and A. P. Gasch, "Stress-activated genomic expression changes serve a preparative role for impending stress in yeast," Molecular Biology of the Cell, vol. 19, no. 11, pp. 4580-4587, 2008 . 
[7] H. Semchyshyn, O. Abrat, Y. Inoue, J. Miedzobrodzki, and V. Lushchak, "Acetate but not propionate induces oxidative stress in bakers' yeast Saccharomyces cerevisiae," Redox Report, vol. 16, no. 1, pp. 15-23, 2011.

[8] J. M. Davies, C. V. Lowry, and K. J. Davies, "Transient adaptation to oxidation stress in yeast," Archives of Biochemistry and Biophysics, vol. 317, no. 1, pp. 1-6, 1995.

[9] C. Godon, G. Lagniel, J. Lee et al., "The $\mathrm{H}_{2} \mathrm{O}_{2}$ stimulon in Saccharomyces cerevisiae," The Journal of Biological Chemistry, vol. 273, no. 35, pp. 22480-22489, 1998.

[10] F. Estruch, "Stress-controlled transcription factors, stressinduced genes and stress tolerance in budding yeast," FEMS Microbiology Reviews, vol. 24, no. 4, pp. 469-486, 2000.

[11] Q. Guan, S. Haroon, D. G. Bravo, J. L. Will, and A. P. Gasch, "Cellular memory of acquired stress resistance in Saccharomyces cerevisiae," Genetics, vol. 192, no. 2, pp. 495-505, 2012.

[12] K. A. Morano, C. M. Grant, and W. S. Moye-Rowley, "The response to heat shock and oxidative stress in Saccharomyces cerevisiae," Genetics, vol. 190, no. 4, pp. 1157-1195, 2012.

[13] H. Semchyshyn, "Hydrogen peroxide-induced response in $E$. coli and S. cerevisiae: different stages of the flow of the genetic information," Central European Journal of Biology, vol. 4, no. 2, pp. 142-153, 2009.

[14] V. I. Lushchak, "Oxidative stress in yeast," Biochemistry, vol. 75, no. 3, pp. 281-296, 2010.

[15] J. Lee, C. Godon, G. Lagniel et al., "Yap1 and Skn7 control two specialized oxidative stress response regulons in yeast," The Journal of Biological Chemistry, vol. 274, no. 23, pp. 1604016046, 1999.

[16] L. P. Collinson and I. W. Dawes, "Inducibility of the response of yeast cells to peroxide stress," Journal of General Microbiology, vol. 138, no. 2, pp. 329-335, 1992.

[17] A. Delaunay, A.-D. Isnard, and M. B. Toledano, " $\mathrm{H}_{2} \mathrm{O}_{2}$ sensing through oxidation of the Yap1 transcription factor," The EMBO Journal, vol. 19, no. 19, pp. 5157-5166, 2000.

[18] E. Herrero, J. Ros, G. Bellí, and E. Cabiscol, "Redox control and oxidative stress in yeast cells," Biochimica et Biophysica Acta, vol. 1780, no. 11, pp. 1217-1235, 2008.

[19] H. M. Semchyshyn and L. M. Lozinska, "Fructose protects baker's yeast against peroxide stress: potential role of catalase and superoxide dismutase," FEMS Yeast Research, vol. 12, no. 7, pp. 761-773, 2012.

[20] M. Chandler, G. A. Stanley, P. Rogers, and P. Chambers, "A genomic approach to defining the ethanol stress response in the yeast Saccharomyces cerevisiae," Annals of Microbiology, vol. 54, no. 4, pp. 427-454, 2004.

[21] I. Bleoanca, A. R. Silva, C. Pimentel, C. Rodrigues-Pousada, and R. D. Menezes, "Relationship between ethanol and oxidative stress in laboratory and brewing yeast strains," Journal of Bioscience and Bioengineering, vol. 116, no. 6, pp. 697-705, 2013.

[22] Y. Inoue, T. Matsuda, K.-I. Sugiyama, S. Izawa, and A. Kimura, "Genetic analysis of glutathione peroxidase in oxidative stress response of Saccharomyces cerevisiae," The Journal of Biological Chemistry, vol. 274, no. 38, pp. 27002-27009, 1999.

[23] C. D. Holyoak, D. Bracey, P. W. Piper, K. Kuchler, and P. J. Coote, "The Saccharomyces cerevisiae weak-acid-inducible ABC transporter Pdr12 transports fluorescein and preservative anions from the cytosol by an energy- dependent mechanism," Journal of Bacteriology, vol. 181, no. 15, pp. 4644-4652, 1999.

[24] N. Guaragnella, L. Antonacci, S. Passarella, E. Marra, and S. Giannattasio, "Hydrogen peroxide and superoxide anion production during acetic acid-induced yeast programmed cell death," Folia Microbiologica, vol. 52, no. 3, pp. 237-240, 2007.

[25] V. I. Lushchak, O. B. Abrat, J. Międzobrodzki, and H. M. Semchyshyn, "Pdr12p-dependent and -independent fluorescein extrusion from baker's yeast cells," Acta Biochimica Polonica, vol. 55, no. 3, pp. 595-601, 2008.

[26] O. B. Abrat, H. M. Semchyshyn, J. Miedzobrodzki, and V. I. Lushchak, "Fluorescein transport and antioxidant systems in the yeast Saccharomyces cerevisiae under acid stress," Ukrainian Biochemical Journal, vol. 80, no. 3, pp. 70-77, 2008.

[27] A. Conconi, P. Jager-Vottero, X. Zhang, B. C. Beard, and M. J. Smerdon, "Mitotic viability and metabolic competence in UVirradiated yeast cells," Mutation Research, vol. 459, no. 1, pp. 5564, 2000.

[28] J. A. Imlay and S. Linn, "Mutagenesis and stress responses induced in Escherichia coli by hydrogen peroxide," Journal of Bacteriology, vol. 169, no. 7, pp. 2967-2976, 1987.

[29] R. M. Day and Y. J. Suzuki, "Cell proliferation, reactive oxygen and cellular glutathione," Dose Response, vol. 3, no. 3, pp. 425442, 2006.

[30] E. J. Calabrese, "Hormesis and medicine," British Journal of Clinical Pharmacology, vol. 66, no. 5, pp. 594-617, 2008.

[31] E. J. Calabrese, "Once marginalized, evidence now supports hormesis as the most fundamental dose response," in Hormesis: A Revolution in Biology, Toxicology and Medicine, M. P. Mattson and E. J. Calabrese, Eds., pp. 15-56, Humana Press, New York, NY, USA, 2010.

[32] E. J. Calabrese and L. A. Baldwin, "Ethanol and hormesis," Critical Reviews in Toxicology, vol. 33, no. 3-4, pp. 407-424, 2003.

[33] A. Kurta and B. G. Palestis, "Effects of ethanol on the shoaling behavior of Zebrafish (Danio rerio)," Dose-Response, vol. 8, no. 4, pp. 527-533, 2010.

[34] M. B. Toledano, A. Delaunay, L. Monceau, and F. Tacnet, "Microbial $\mathrm{H}_{2} \mathrm{O}_{2}$ sensors as archetypical redox signaling modules," Trends in Biochemical Sciences, vol. 29, no. 7, pp. 351-357, 2004.

[35] H. J. Forman, "Reactive oxygen species and $\alpha, \beta$-unsaturated aldehydes as second messengers in signal transduction," Annals of the New York Academy of Sciences, vol. 1203, pp. 35-44, 2010.

[36] E. A. Veal, A. M. Day, and B. A. Morgan, "Hydrogen peroxide sensing and signaling," Molecular Cell, vol. 26, no. 1, pp. 1-14, 2007.

[37] K. Vandenbroucke, S. Robbens, K. Vandepoele, D. Inzé, Y. van de Peer, and F. van Breusegem, "Hydrogen peroxide-induced gene expression across kingdoms: a comparative analysis," Molecular Biology and Evolution, vol. 25, no. 3, pp. 507-516, 2008.

[38] E. A. Veal and A. M. Day, "Hydrogen peroxide as a signaling molecule," Antioxidants \& Redox Signaling, vol. 15, no. 1, pp. 147151, 2011.

[39] J. Chiu and I. W. Dawes, "Redox control of cell proliferation," Trends in Cell Biology, vol. 22, no. 11, pp. 592-601, 2012. 

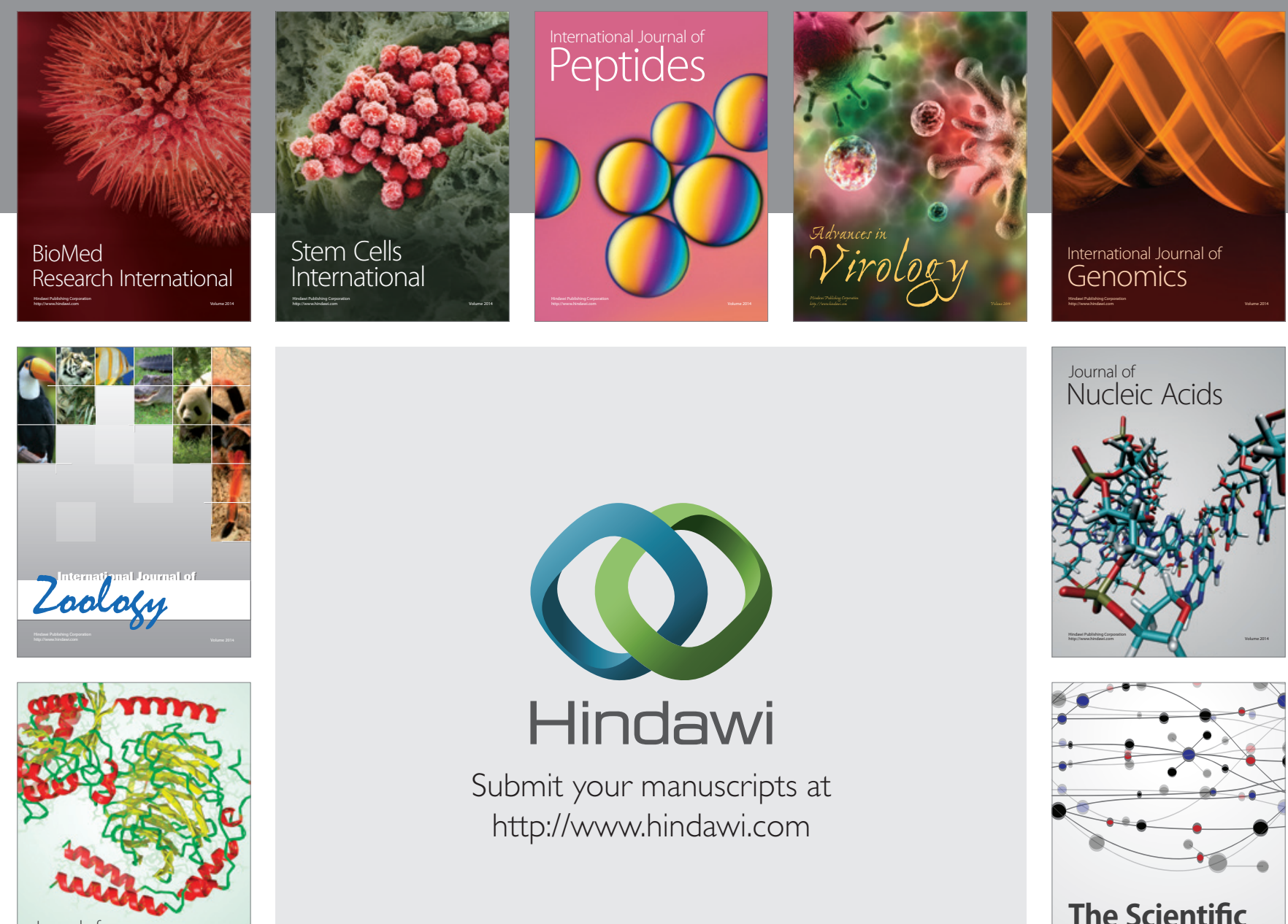

Submit your manuscripts at

http://www.hindawi.com

Journal of
Signal Transduction
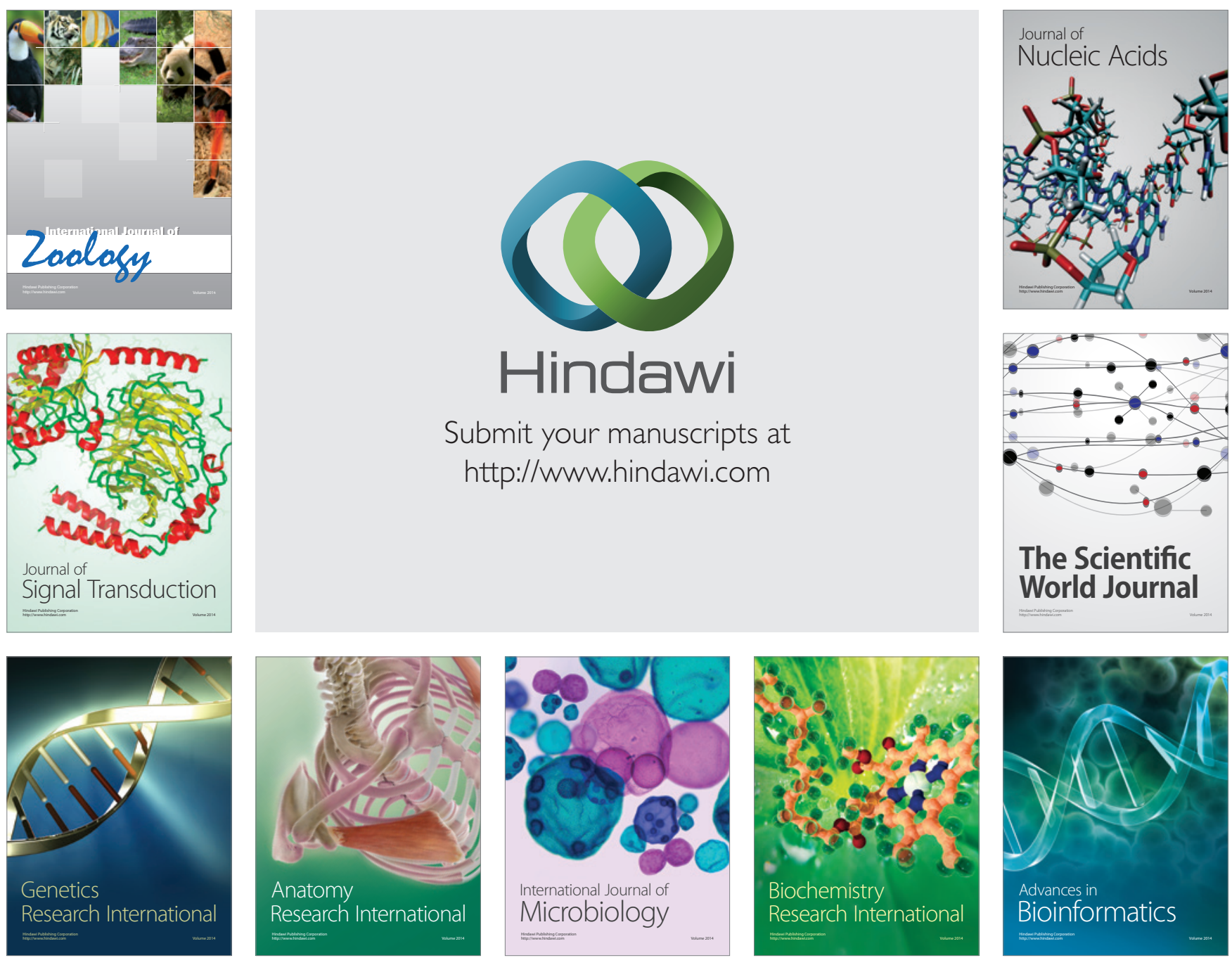

The Scientific World Journal
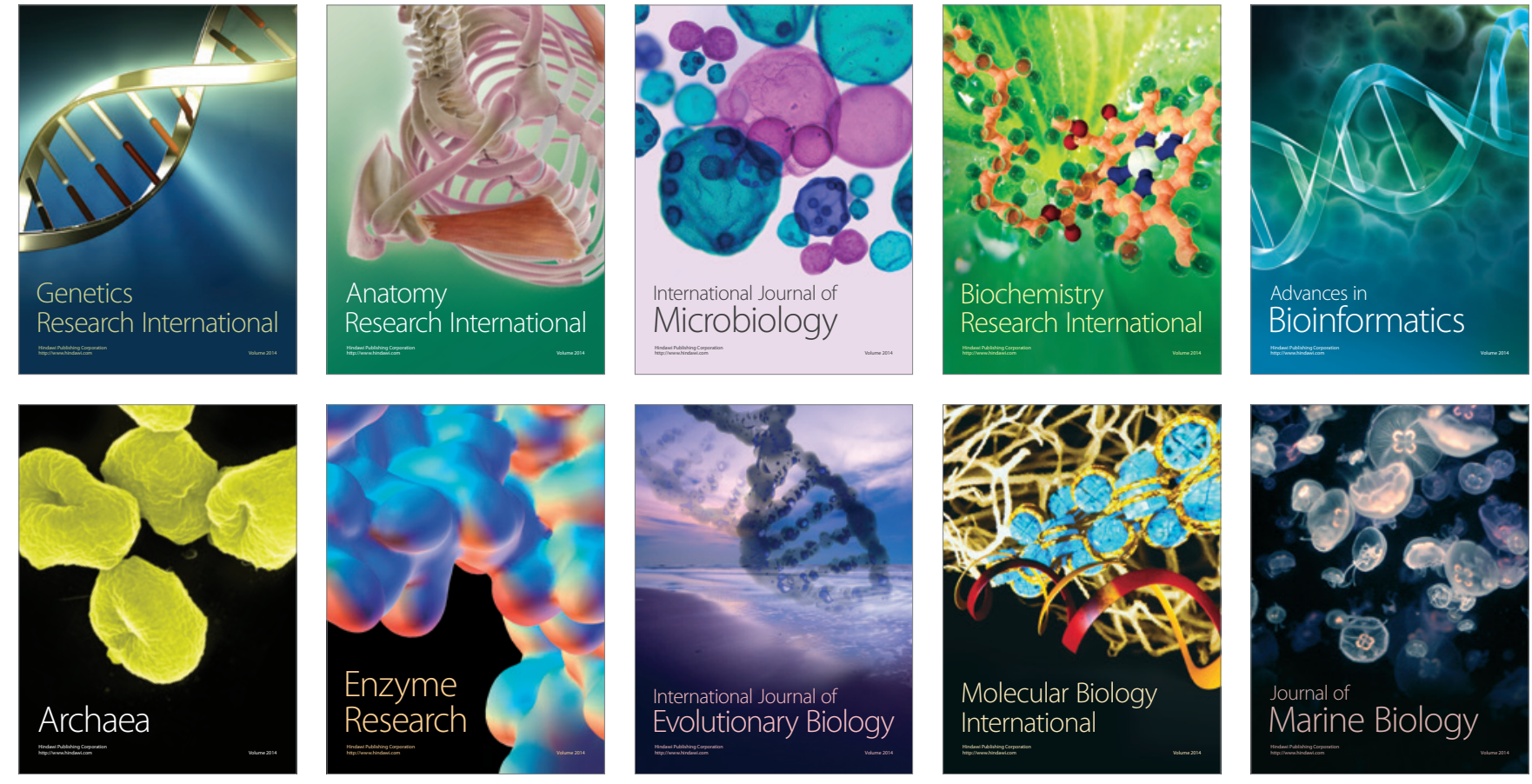